\title{
Formation of secondary organic aerosols from the ozonolysis of dihydrofurans.
}

Yolanda Díaz-de-Mera, Alfonso Aranda*, Larisa Bracco, Diana Rodríguez and Ana Rodríguez.

\section{Supplementary Material.}

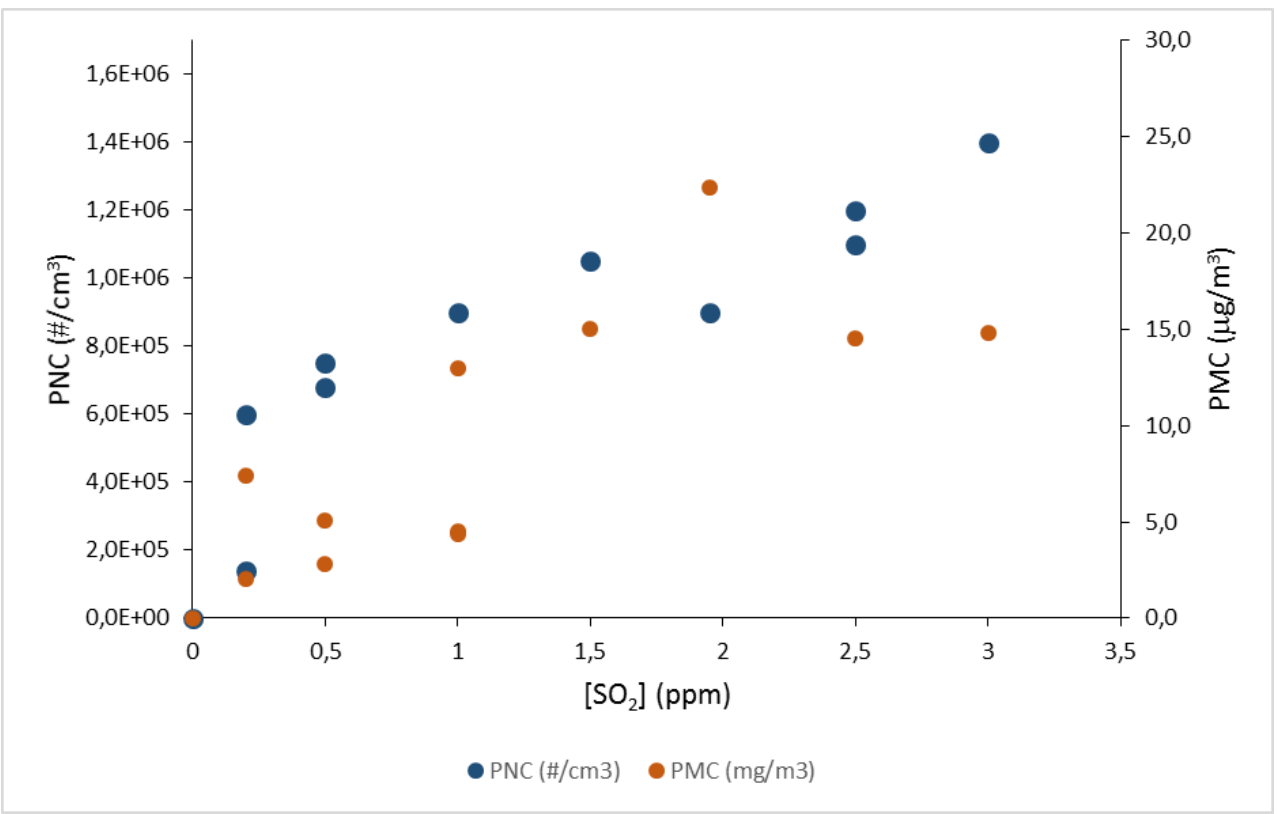

Figure S1. Maximum particle number concentration and maximum mass concentration in experiments with different $\mathrm{SO}_{2}$ initial concentrations. For this series of experiments, the initial concentrations of 2,5-DHF and ozone were 0.5 and 1.0 ppm respectively. Relative humidity $=0$.

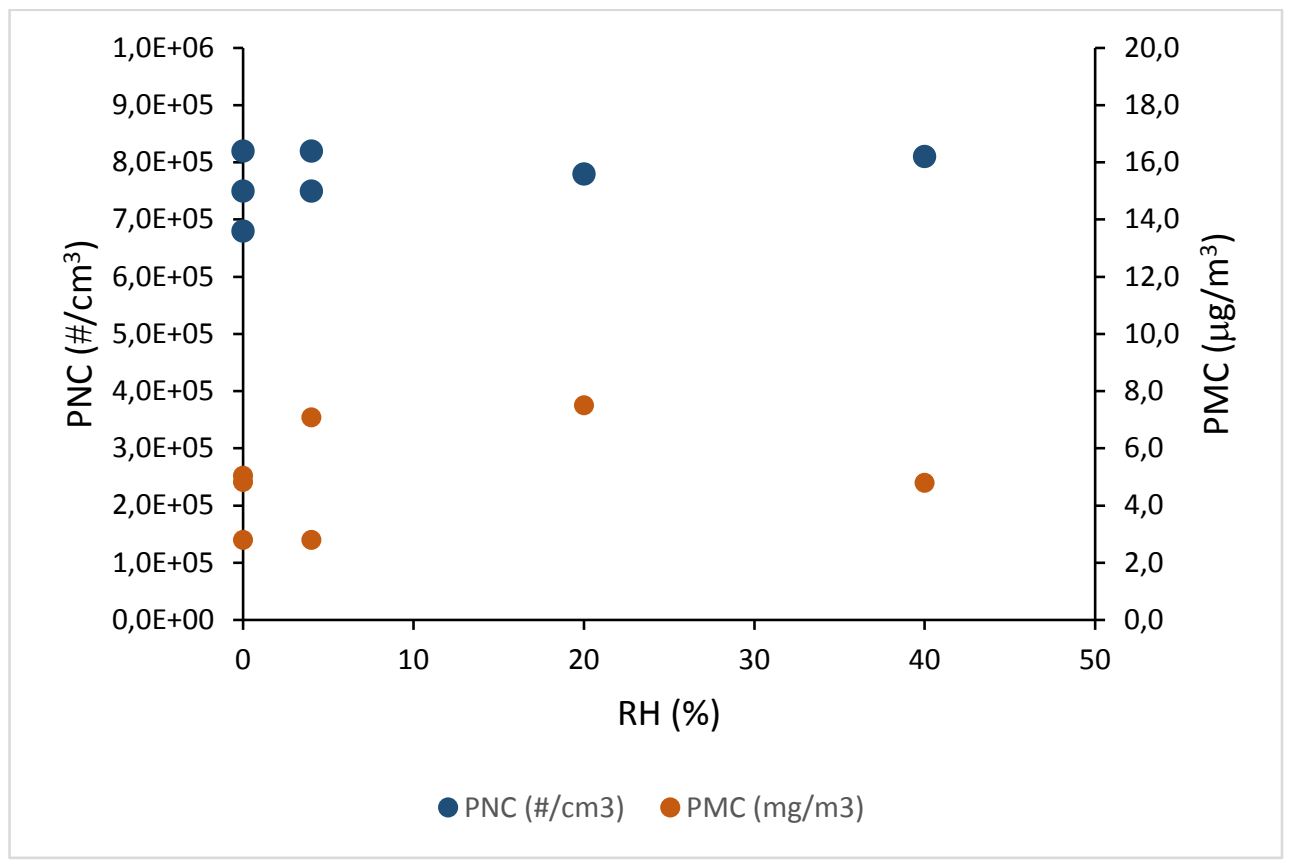

Figure S2. Maximum particle number concentration and maximum mass concentration in experiments carried out under different RH. For this series of experiments, the initial concentrations of 2,5-DHF, ozone and $\mathrm{SO}_{2}$ were $0.5,1.0$ and 0.5 ppm respectively. 
Effect of ozone and 2,5-DHF initial concentrations.

Several experiments were also carried out to find the effect of concentrations of ozone and 2,5-DHF on the production of SOA. Keeping fixed concentrations of $\mathrm{SO}_{2}$ and 2,5-DHF, the increase of ozone lead to increase of the particles number concentration and mass concentration, as it is shown in figure S3.

Likewise, keeping constant the $\mathrm{SO}_{2}$ and ozone initial concentrations, an increase of 2,5-DHF lead to the increase of both PNC and PMC, figure S4. Both ozone and 2,5-DHF dependences suggest that their primary reaction is closely coupled to the production of particles. The acceleration of the reaction of ozone with 2,5-DHF enhances the formation of particles. In this sense, the SOA yield, defined as the ratio between the total mass concentration and the total concentration of reacted 2,5-DHF, for any experiment was linear for most of the reaction time, Figure S5.

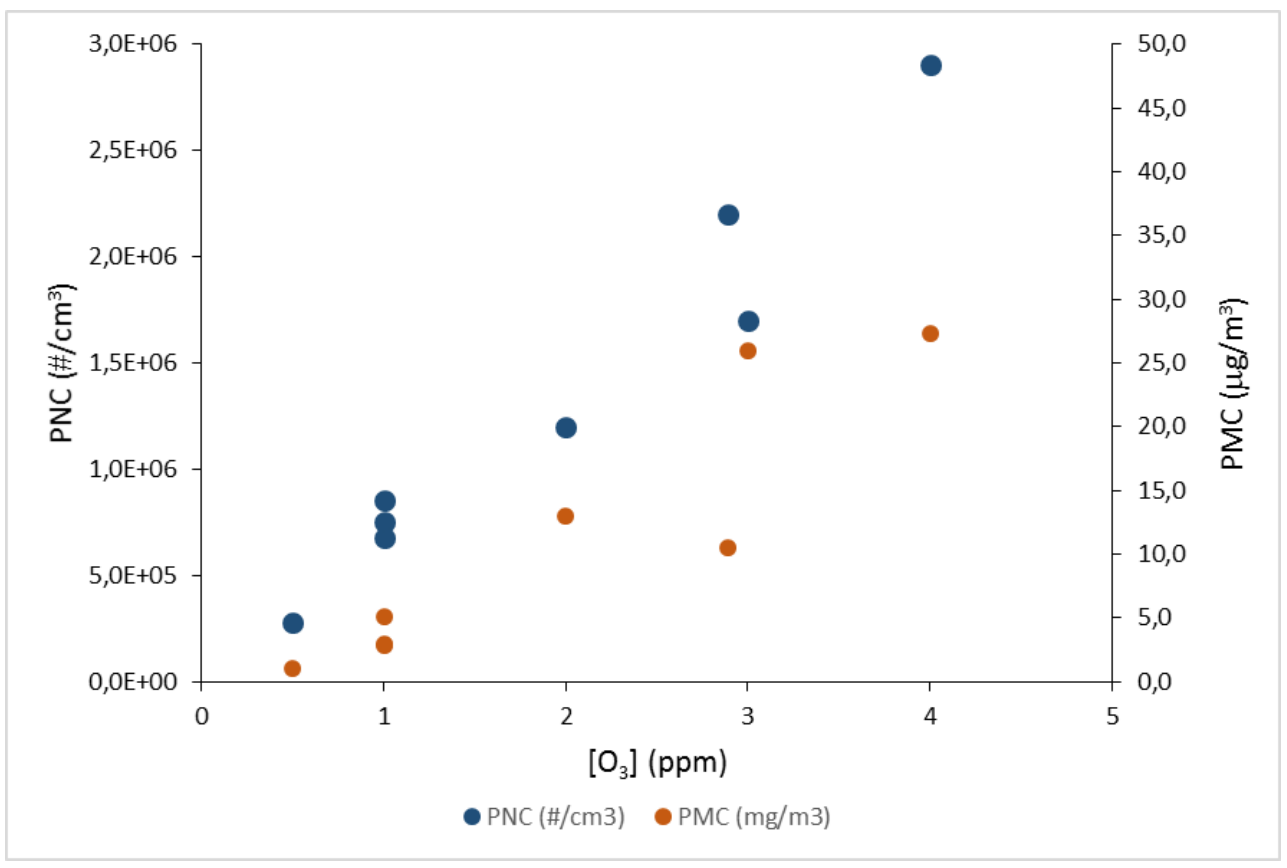

Figure S3. Maximum particle number concentration and maximum mass concentration in experiments carried out under different ozone concentrations. For this series of experiments, the initial concentrations of 2,5-DHF and $\mathrm{SO}_{2}$ were 0.5 ppm and $\mathrm{RH}=0$. 


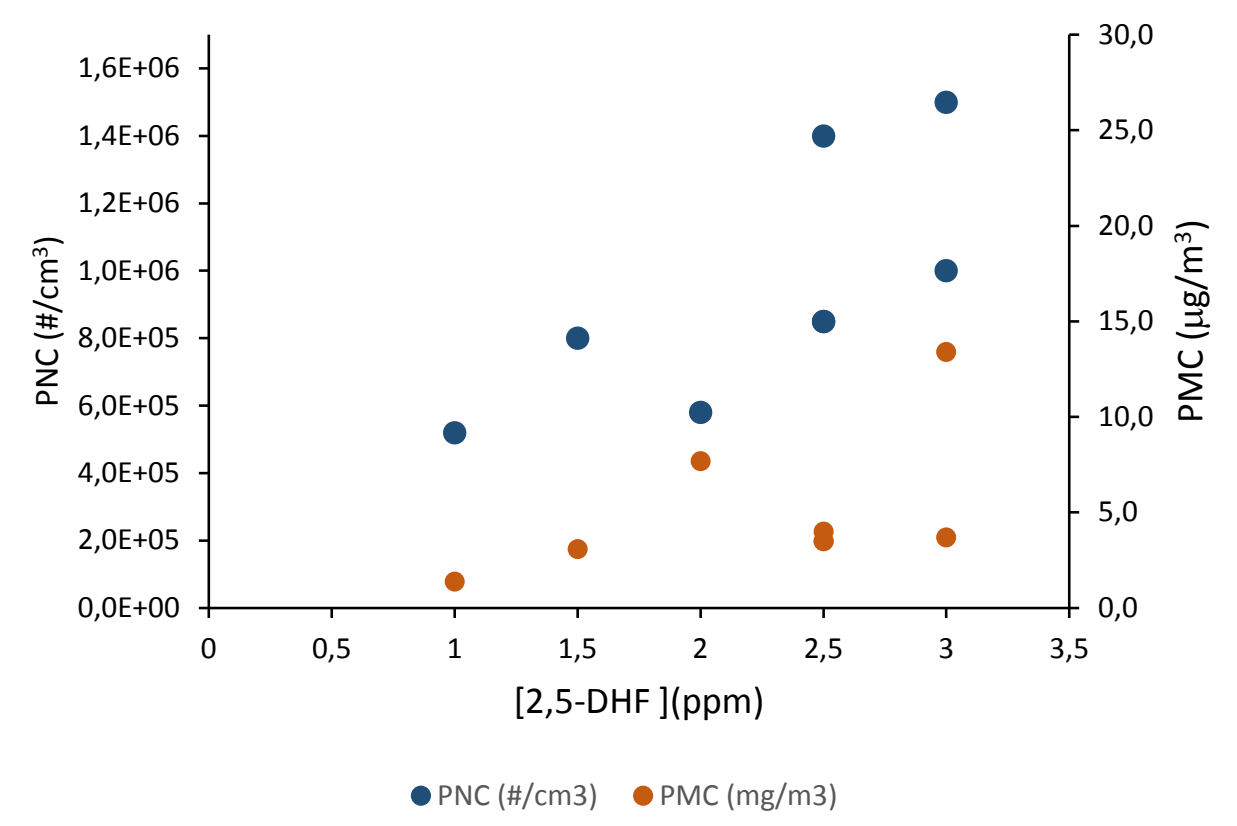

Figure S4. Maximum particle number concentration and maximum mass concentration in experiments carried out under different 2,5-DHF concentrations. For this series of experiments, the initial concentrations of ozone and $\mathrm{SO}_{2}$ were $0.5 \mathrm{ppm}$. $\mathrm{RH}=0$.

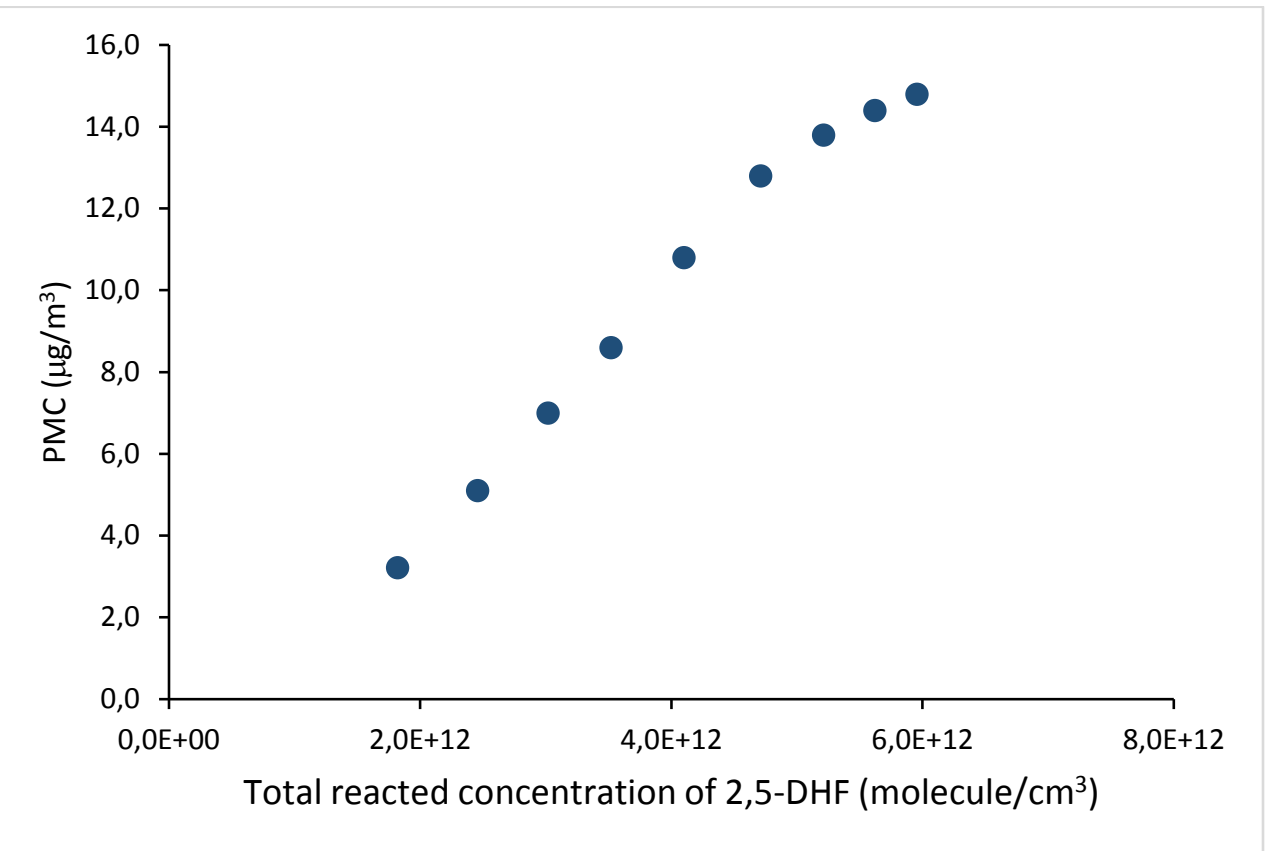

Figure S5. Particle mass concentration formed during a typical experiment against the total concentration of reacted 2,5-DHF. 


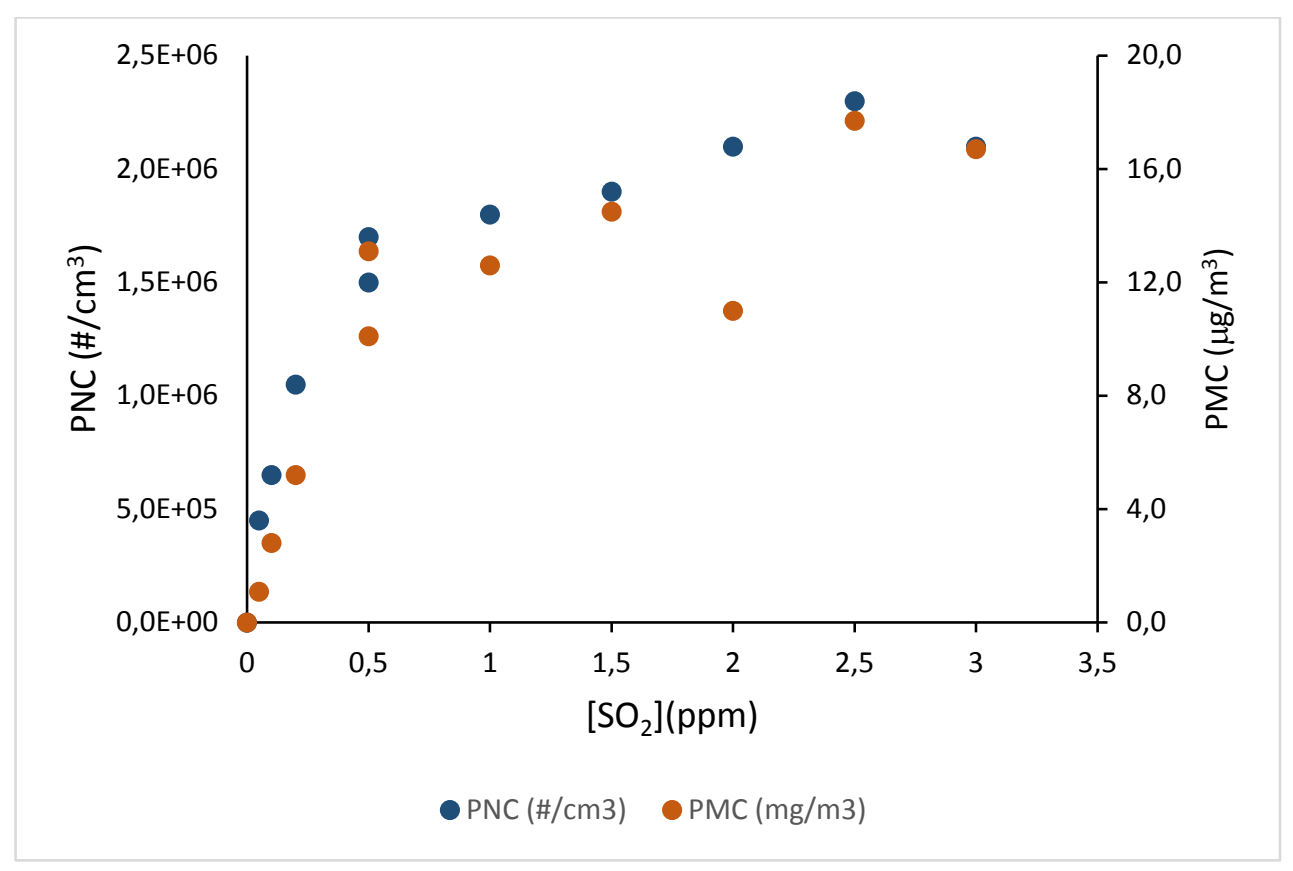

Figure S6. Maximum particle number concentration and maximum mass concentration in experiments with different $\mathrm{SO}_{2}$ initial concentrations. For this series of experiments, the initial concentrations of 2,3-DHF and ozone were 0.5 and 1.0 ppm respectively. Relative humidity $=0$.

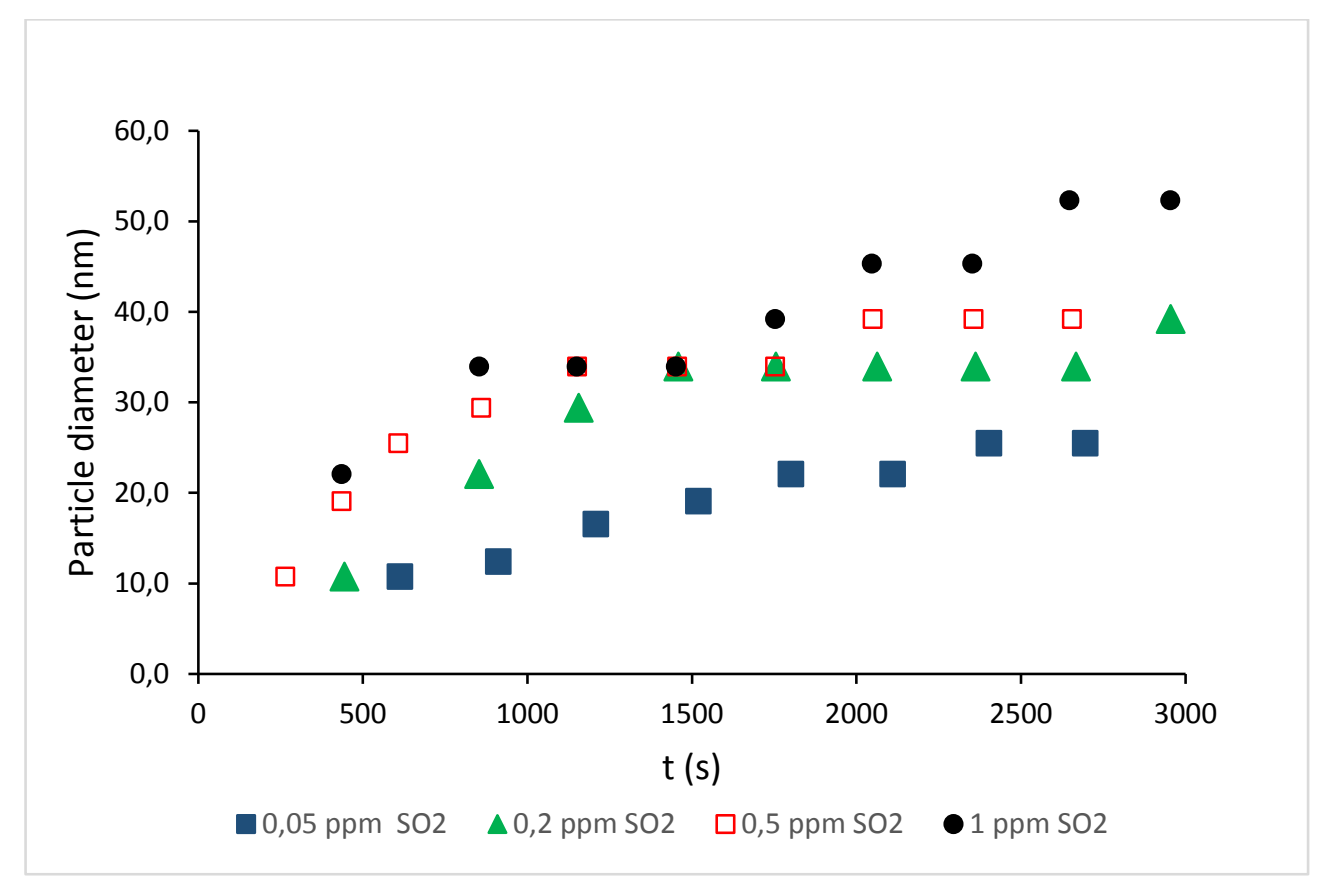

Figure S7. Average particles' diameters growth for some experiments with 0.5 ppm of 2,3-DHF and 1 ppm of ozone initial concentrations under dry conditions and variable $\mathrm{SO}_{2}$. 


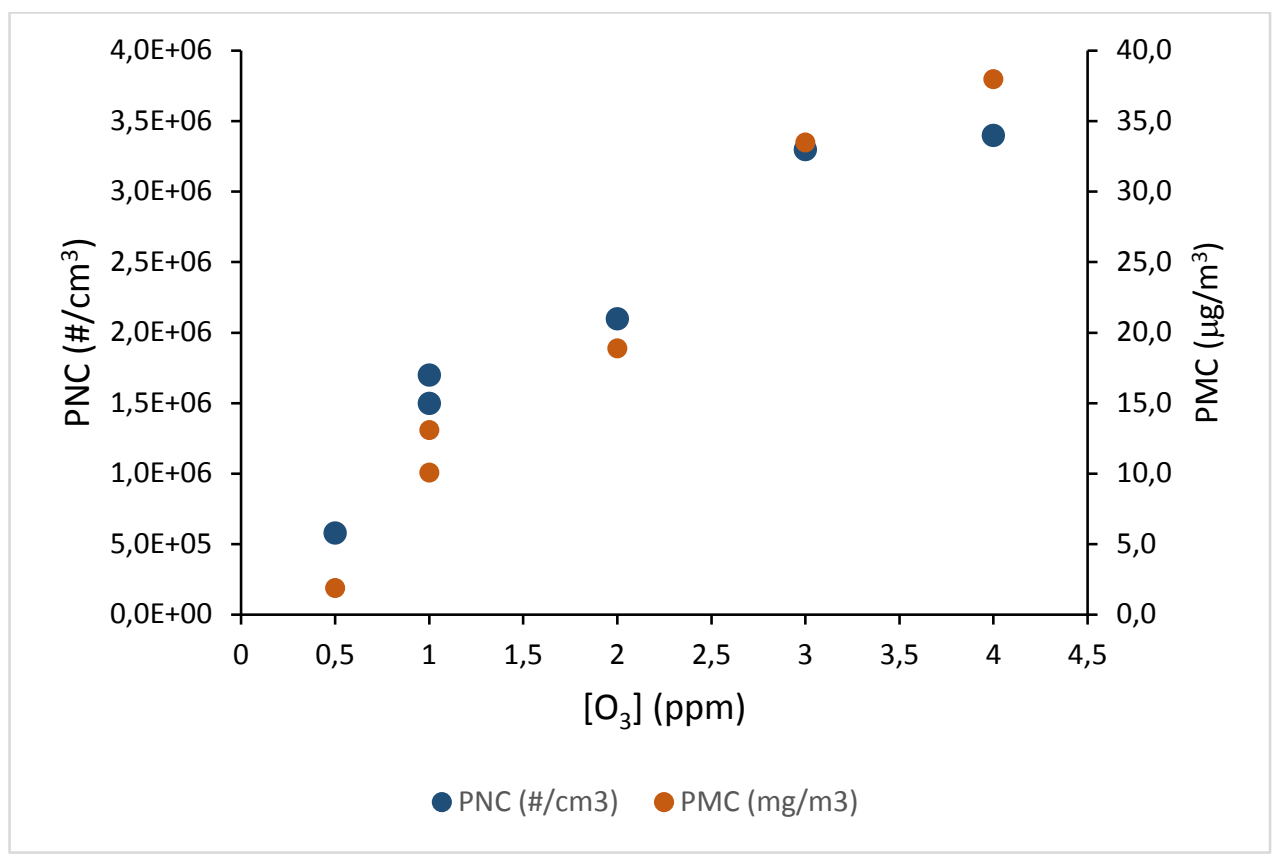

Figure S8. Maximum particle number concentration and maximum particle mass concentration in experiments carried out under different ozone concentrations and dry conditions. For this series of experiments, the initial concentrations of 2,3-DHF and and $\mathrm{SO}_{2}$ were $0.5 \mathrm{ppm}$.

Table ST1. Effect of water vapour on the SOA production for the ozonolysis of 2,3-DHF. Initial concentrations of reactants and SOA data. PNC, PMC and diameter reported values are the maximum data registered for each magnitude during the experiment.

\begin{tabular}{ccccccc}
\hline $\begin{array}{c}\mathbf{2 , 3 - D H F} \\
\mathbf{( p p m )}\end{array}$ & $\begin{array}{c}\mathbf{O}_{3} \\
\mathbf{( p p m )}\end{array}$ & $\begin{array}{c}\mathbf{S O}_{2} \\
\mathbf{( p p m )}\end{array}$ & $\begin{array}{c}\text { HR } \\
\mathbf{( \% )}\end{array}$ & $\begin{array}{c}\text { PNC } \\
\left(\mathbf{\#} / \mathbf{c m}^{3}\right)\end{array}$ & $\begin{array}{c}\text { PMC } \\
\left(\boldsymbol{\mu g} / \mathbf{m}^{3}\right)\end{array}$ & $\begin{array}{c}\text { Diameter } \\
(\mathbf{n m})\end{array}$ \\
\hline 0.5 & 1 & 0 & 20 & 3.9 & 0 & 0 \\
0.5 & 1 & 0 & 50 & 38 & 0 & 0 \\
0.5 & 1 & 0 & 5 & 6.7 & 0 & 0 \\
0.5 & 1 & 0 & 50 & 13 & 0 & 0 \\
0.5 & 1 & 0.5 & 0 & $1.70 \times 10^{6}$ & 10.1 & 40 \\
0.5 & 1 & 0.5 & 0 & $1.50 \times 10^{6}$ & 13.1 & 50 \\
0.5 & 1 & 0.5 & 15 & $1.25 \times 10^{6}$ & 9.1 & 50 \\
0.5 & 1 & 0.5 & 15 & $1.20 \times 10^{6}$ & 8.4 & 40 \\
0.5 & 1 & 0.5 & 29.2 & $8.50 \times 10^{5}$ & 4.8 & 35 \\
0.5 & 1 & 0.5 & 31.3 & $6,00 \times 10^{5}$ & 4.0 & 35 \\
0.5 & 1 & 0.5 & 50 & $6,50 \times 10^{5}$ & 3.1 & 35 \\
0.5 & 1 & 0.5 & 50.8 & $6,50 \times 10^{5}$ & 3 & 35
\end{tabular}




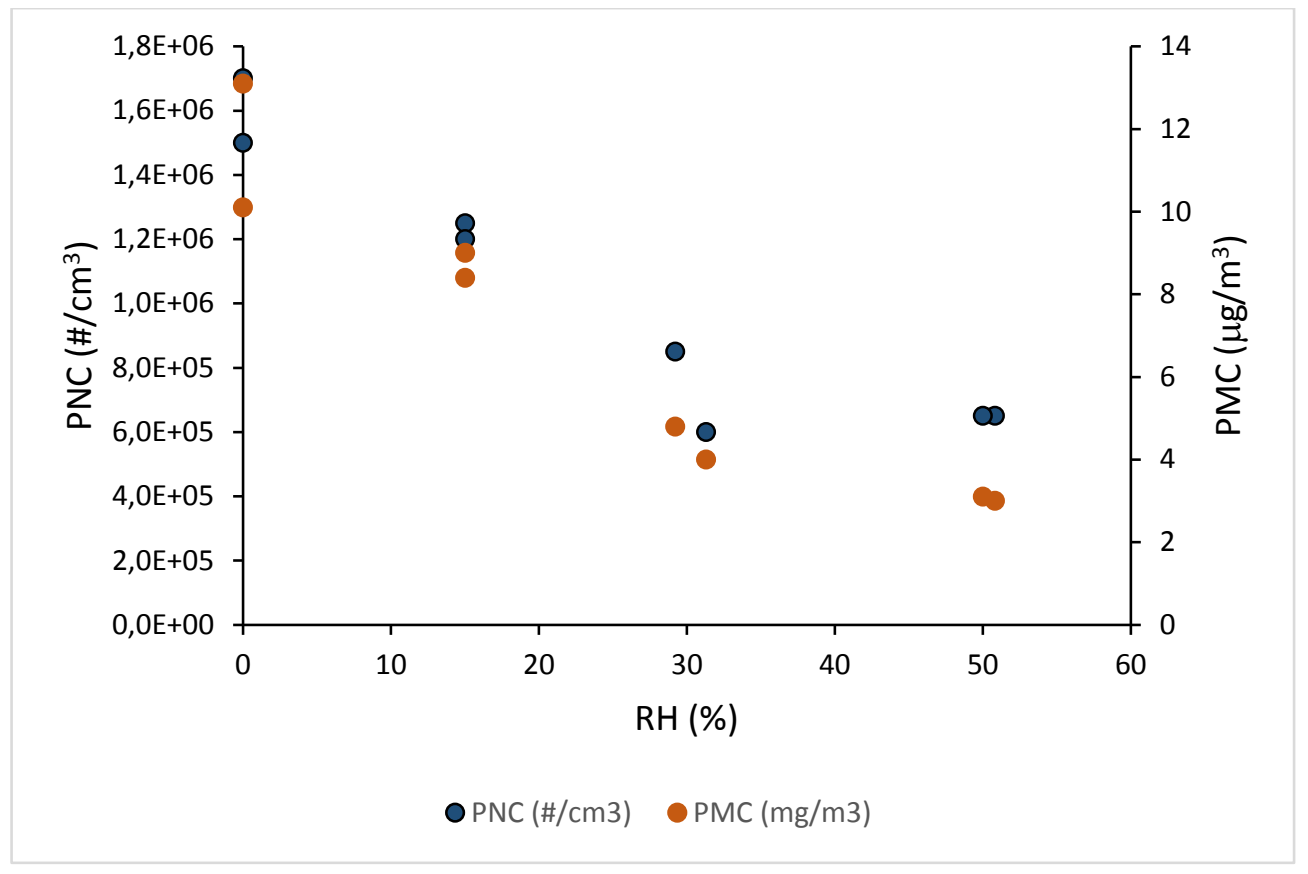

Figure S9. Effect of water vapour. Maximum particle number concentration and maximum particle mass concentration in experiments carried out under different RH. For this series of experiments, the initial concentrations of 2,3-DHF, ozone and $\mathrm{SO}_{2}$ were $0.5,1.0$ and $0.5 \mathrm{ppm}$, respectively.

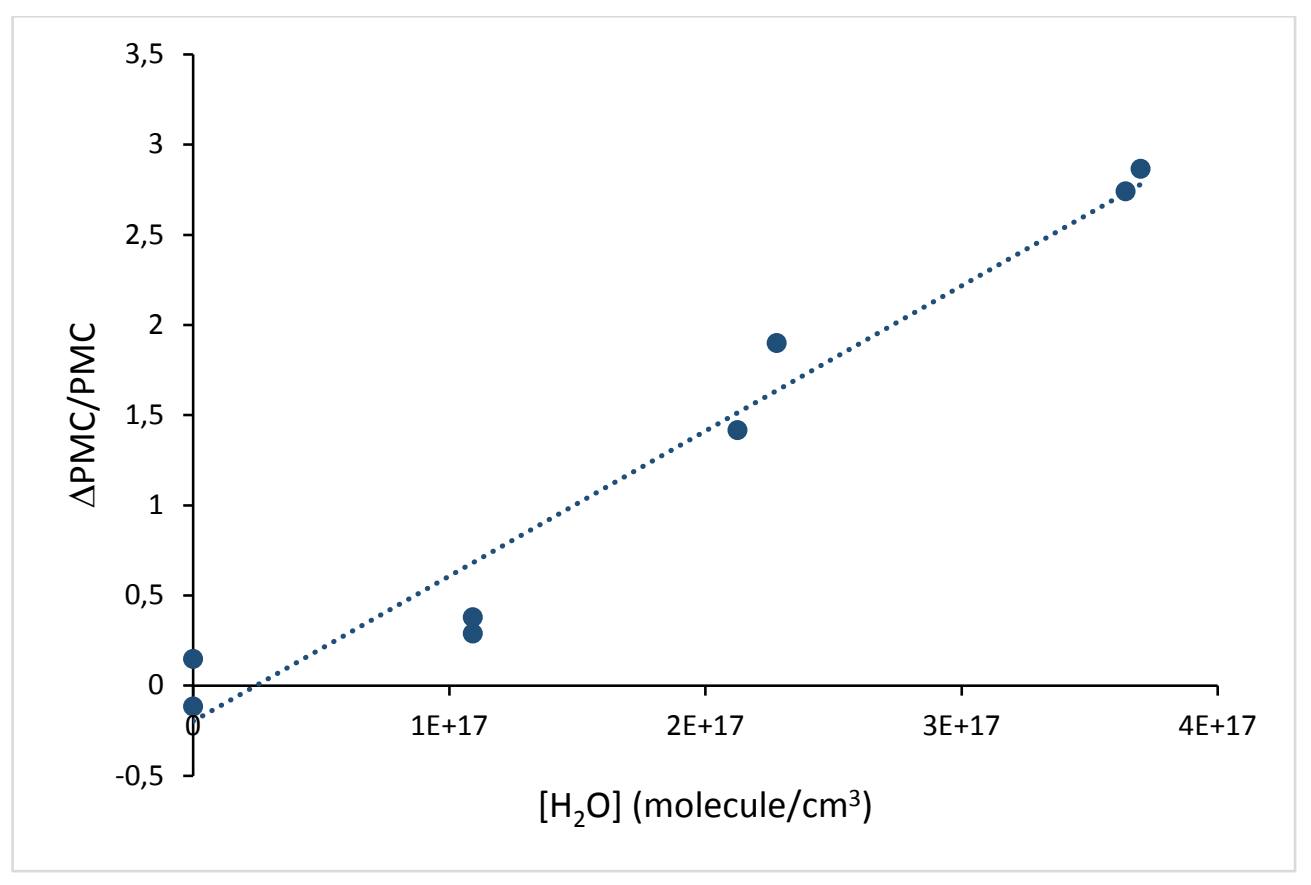

Figure S10. Decrease of the particle mass concentration with respect to the reference (dry) conditions over the actual PMC value for different water concentration. The $\mathrm{SO}_{2}$ concentration for this series of experiments was $1,2 \times{ }^{13}$ molecule $\mathrm{cm}^{-3}$. 